\title{
ANALISIS PENGURANGAN COOLING WATER LOSS MENGGUNAKAN SIX SIGMA DAN FAILURE MODE EFFECT ANAL YSIS (FMEA)
}

\author{
Ikhsan Wicaksono, Tri Joko Wibowo, M. Jihan Shofa \\ Program Studi Teknik Industri, Fakultas Teknik, Universitas Serang Raya \\ Email: ikhsan.wicaksono@gmail.com; rb.bowo@gmail.com; m.j.shofa@gmail.com
}

\begin{abstract}
Abstrak - Loss pada suatu sistem kerja merupakan salah satu penyebab biaya proses membengkak. Loss yang mencapai lebih dari 450 ton/bulan pada cooling water system pada sebuah perusahaan kimia di daerah Serang menyebabkan pengeluaran perusahaan membengkak. Penelitian ini bertujuan untuk mengetahui penyebab cooling water wash sebagai dasar perbaikan proses dengan menggunakan metode Six Sigma dan Failure Mode Effect Analysis (FMEA) Hasil analisa data diperoleh penyebab cooling water loss adalah durasi backwash filter terlalu sedikit, durasi filter service belum optimum, dan flow side stream tidak terbaca. Perbaikan dengan cara memperlama durasi backwash, menaikan waktu servis sand filter menjadi dua hari sekali, dan membersihkan rotameter mampu meningkatkan nilai sigma dari 3,5 menjadi 4,5.
\end{abstract}

Kata kunci: Cooling Water System; Failure Mode Effect Analysis (FMEA); Six Slgma

\begin{abstract}
Loss on a working system is one of the causes of the cost of the process to swell. The loss that reaches more than 450 tons/month on a cooling water system at a chemical company in the Serang area causes the company's expenses to swell. This study aims to determine the cause of cooling water wash as a basis for process improvement by using Six Sigma and Failure Mode Effect Analysis (FMEA). Data analysis results showed that cooling water loss is too little backwash filter duration, service filter duration is not optimum, and flow unreadable side stream. Improvements by increasing the length of the backwash, raising the service time of the sand filter to every two days, and cleaning the rotameter can increase the sigma value from 3.5 to 4.5 .
\end{abstract}

Keywords: Cooling Water System; Failure Mode Effect Analysis (FMEA); Six Slgma

\section{PENDAHULUAN}

Seiring berkembangnya sistem dan teknologi di dunia industri secara global menyebabkan persaingan antar perusahaan semakin ketat. Setiap perusahaan harus dapat bersaing untuk dapat menjaga kualitas produknya sehingga mampu bertahan dalam persaingan di dunia industri. Dalam persaingan di industri manufaktur peranan konsumen sangat penting, karena nilai kepuasan konsumen harus terpenuhi. Untuk menjaga kepuasan konsumen, perusahaan harus mampu membuat produk berkualitas serta meminimalkan inefisiensi proses sehingga harga produk bisa berkompetitif (Windarti, 2014).

Pengendalian kualitas mempunyai peranan yang sangat penting dalam peningkatan kualitas produk agar tidak terjadi penyimpangan yang menyebabkan cacat produk (Rosihin, Ulinnuha, \& Cahyadi, 2017; Supriyadi, Ramayanti, \& Aditia, 2017) Departemen Kualitas adalah sebuah departemen dalam perusahaan yang bertugas untuk melakukan pemantauan produk dalam suatu proses manufaktur, mulai dari penerimaan bahan baku, pembuatan produk, hingga produk tersebut sampai ke konsumen. Juga memantau kualitas produk secara berkala hingga masa akhir penggunaannya.

Tolak ukur yang bisa digunakan untuk melihat apakah perusahaan berhasil dalam upaya menjaga kualitasnya adalah jika perusahaan tersebut berhasil mencapai kondisi Zero defect, akan tetapi sangat sulit untuk mencapai kondisi tersebut, karena produk yang cacat pasti ada walaupun sedikit. $\mathrm{Hal}$ ini disebabkan adanya penyimpangan dalam proses produksi, metode pengontrolan kualitas yang kurang tepat, atau human error. Kejadian ini menyebabkan berkurangnya kepercayaan konsumen terhadap suatu perusahaan sehingga dapat mengurangi keuntungan yang didapat serta kehilangan konsumen. Berbagai cara untuk mengurangi defect, salah satunya dengan implementasi perbaikan menggunakan Six Sigma 
(DMAIC) untuk memetakan alur pengerjaan serta mengevaluasi hasil pada tahapan implementasi.

Metode Six Sigma merupakan sistem pengendalian kualitas dalam mengurangi variasi proses dengan menggunakan cara yang terstruktur dan metrik kinerja dalam mencapai sasaran yang telah ditetapkan (Kwak \& Anbari, 2006; Schroeder, Linderman, Liedtke, \& Choo, 2008) berdasarkan tahapan DMAIC (Define, Measure, Analyze, Improve, and Control) (Chakravorty, 2009; Pyzdek \& Keller, 2010). six sigma berfokus pada perbaikan proses sehingga peluang terjadinya cacat dapat diantisipasi sebelum cacat tersebut terjadi (Antony, 2006).

Secara umum utilitas loss yang ada di sebuah perusahaan kimia di daerah serang ada yang tidak mungkin dikurangi karena memang merupakan kondisi keharusan dari keadaan plant seperti electricity, instrument air, dan plant air. Ada juga yang bisa dikurangi jumlahnya tanpa harus mengganggu proses produksi diantaranya adalah cooling water waste, waste water, dan waste residu. Penelitian ini bertujuan menganalisa penyebab loss tertinggi di perusahaan yaitu mengurangi cooling water waste. Hasil rekomendasi perbaikan yang dilakukan diharapkan mampu meminimalkan loss yang terjadi.

\section{METODE PENELITIAN}

Penelitian menggunakan metode six sigma dalam menganalisa permasalahan loss yang terjadi di sebuah perusahaan kimia di daerah serang. Data yang digunakan dalam penelitian ini adalah data data cooling water loss bulan mei 2017 - september 2017. Tahapan six sigma yang digunakan berdasarkan tahapan DMAIC (Define, Measure, Analyze, Improve, Control).

Tahap define merupakan tahapan pertama dari proses six sigma yang terdiri penentuan target dan tujuan yang hendak dicapai (Rohimudin, Dwiputra, \& Supriyadi, 2016). Pada tahapan ini team akan menetapkan proyek six sigma yang akan menjadi prioritas kerja.

Tahapan measure merupakan poin kritikal yang sangat berpengaruh terhadap hasil yang akan dicapai. Pada tahapan ini akan ditentukan nilai CTQ dan penentuan baseline kinerja saat ini sebagai dasar penentuan target baseline kinerja selanjutnya.

Tahap analyzemerupakan tahapan mencari akar penyebab masalah dari hasil baseline kinerja yang saat ini tercapai. Akar penyebab masalah tersebut kemudian di analisa dengan cara brainstorming dengan karyawan untuk menentukan nilai Severity, Occurance, dan Detection (tabel 1-3)
Tabel 1. Tingkat Keparahan (Severity)

\begin{tabular}{|c|c|c|}
\hline Severity & Kriteria & Rating \\
\hline & Bentuk kegagalan & \\
\hline Tinggi & $\begin{array}{l}\text { membuat cooling water } \\
\text { loss tinggi } \\
\text { Bentuk kegagalan akan }\end{array}$ & 10 \\
\hline Tinggi & $\begin{array}{l}\text { meningkatkan cooling } \\
\text { water loss }\end{array}$ & 7 \\
\hline Moderate & $\begin{array}{l}\text { Bentuk kegagalan } \\
\text { kemungkinan dapat } \\
\text { meningkatkan cooling } \\
\text { water loss dan mungkin } \\
\text { tidak berpengaruh }\end{array}$ & 5 \\
\hline Rendah & $\begin{array}{lr}\text { Bentuk } & \text { kegagalan } \\
\text { mempengaruhi } & \text { cooling } \\
\text { water loss } & \text { tetapi } \\
\text { jumlahnya } & \text { sedikit }\end{array}$ & 3 \\
\hline Terkontrol & $\begin{array}{l}\text { Bentuk kegagalan tidak } \\
\text { akan meningkatkan } \\
\text { cooling water loss }\end{array}$ & 1 \\
\hline
\end{tabular}

Tabel 2. Tingkat Keterjadian (Occurrence)

\begin{tabular}{llc}
\hline Occurrence & \multicolumn{1}{c}{ Kriteria } & Rating \\
\hline $\begin{array}{l}\text { Sangat } \\
\text { Tinggi }\end{array}$ & $\begin{array}{l}\text { Kegagalan hampir tak } \\
\text { terelakkan } \\
\text { Tinggi }\end{array}$ & $\begin{array}{l}\text { Kegagalan terus } \\
\text { berulang }\end{array}$ \\
Moderate & $\begin{array}{l}\text { Kegagalan terjadi } \\
\text { sesekali }\end{array}$ & 7 \\
Rendah & $\begin{array}{l}\text { Kegagalan relatif sedikit } \\
\text { Kegagalan tidak } \\
\text { mungkin terjadi }\end{array}$ & 3 \\
\hline
\end{tabular}

Tabel 3. Tingkat Deteksi (Detection)

\begin{tabular}{|c|c|c|}
\hline Detection & Kriteria & Rating \\
\hline $\begin{array}{l}\text { Sangat } \\
\text { Tinggi }\end{array}$ & $\begin{array}{l}\text { Kemungkinan penyebab } \\
\text { terjadi masih sangat tinggi. } \\
\text { Metode pencegahan tidak } \\
\text { efektif. Penyebab masih } \\
\text { berulang kembali. }\end{array}$ & 10 \\
\hline Tinggi & $\begin{array}{l}\text { Kemungkinan penyebab } \\
\text { terjadi masih tinggi. Metode } \\
\text { pencegahan kurang efektif. } \\
\text { Penyebab masih berulang } \\
\text { kembali. }\end{array}$ & 7 \\
\hline & $\begin{array}{l}\text { Kemungkinan penyebab } \\
\text { terjadi bersifat moderate. }\end{array}$ & \\
\hline Moderate & $\begin{array}{l}\text { Metode pencegahan } \\
\text { kadang memungkinkan } \\
\text { penyebab itu terjadi. }\end{array}$ & 5 \\
\hline Rendah & $\begin{array}{l}\text { Kemungkinan penyebab } \\
\text { terjadi sangat rendah. } \\
\text { Metode pencegahan }\end{array}$ & 3 \\
\hline Terkontrol & $\begin{array}{l}\text { sangat efektif. Tidak ada } \\
\text { kesempatan penyebab } \\
\text { mungkin muncul }\end{array}$ & 1 \\
\hline
\end{tabular}


Tahapan improve merupakan langkah perbaikan yang akan dilakukan untuk mrengurangi varian dan penyebab cacat yang terjadi. Tahapan control merupakan tahap evaluasi keberhasilan program six sigma.

\section{HASIL DAN PEMBAHASAN}

Proses yang terjadi pada cooling water perusahaan adalah cooling water yang berasal dari proses didinginkan kembali dengan cooling tower fan sehingga temperatur mencapai suhu < 31 degC. Setelah didinginkan cooling water disirkulasikan kembali ke proses dengan make up water karena ada sebagian air yang hilang saat pendinginan. Untuk mencegah terjadinya akumulasi lumut, suspended solid dan kotoran lainnya sebagian cooling water dibuang ke PT8805 dan di-make up cooling water baru dari KTI. Selain melakukan blowdown, suspended solid di cooling water system juga dikontrol dengan mengalirkan sebagian water ke sand filter. Akibat adanya pemakaian terus menerus, maka sand filter akan mengalami kejenuhan dan harus dilakukan backwash supaya dapat digunakan kembali. Jumlah air yang dibuang pada normal blowdown dan backwash setiap hari adalah 10 ton, jika jumlahnya lebih dari itu maka akan dianggap sebagai kehilangan. Proses backwash inilah yang menjadi sumber utama coss lost dari sisi utilitas.

\section{Define}

Define merupakan tahap pendefinisian masalah kualitas dalam produk, pada hal ini adanya cost loss yang tinggi. Untuk lebih jelasnya akan diberikan bagaimana poin yang digunakan hingga akhirnya ditetapkan untuk memilih mengurangi cost loss dari cooling water system.

Berdasarkan pengamatan yang telah dilakukan bidang utilitas adalah salah satu sumber penyebab cost loss yang terbesar yaitu mengakibatkan kerugian sebesar 7.37US\$/T-BD. Dengan hasil pengamatan di atas peneliti memutuskan untuk mencoba mengurangi jumlah loss yang terjadi di bidang utilitas.

Dari banyaknya utilitas loss yang ada yang tidak mungkin dikurangi karena memang merupakan kondisi keharusan dari keadaan plant seperti electricity, instrument air, plant air. Ada juga yang bisa dikurangi jumlahnya tanpa harus mengganggu proses produksi diantaranya adalah : cooling water waste, waste water, dan waste residue. Karena jumlahnya yang tinggi maka penelitian difokuskan untuk mengurangi jumlah cooling water.

\section{Measure}

Data yang diambil merupakan total cooling water loss dari bulan Mei 2017 sampai dengan bulan September 2017, dengan jumlah total pemakaian cooling water sebesar 21600 ton setiap bulan. Jumlah loss akan dimasukan sebagai cacat dan total pemakaian cooling water akan dimasukan sebagai total produksi. Berdasarkan hasil perhitungan nilai sigma saat ini diperoleh sebesar 3,5 (Tabel 4). Angka ini menunjukkan masih banyak ruang untuk perbaikan dalam rangka meningkatkan nilai sigma yang diperoleh.

Tabel 4. Nilai Sigma

\begin{tabular}{ccccc}
\hline Bulan & $\begin{array}{c}\text { Jumlah } \\
\text { Produksi }\end{array}$ & $\begin{array}{c}\text { Jumlah } \\
\text { Loss }\end{array}$ & DPMO & $\begin{array}{c}\text { Nilai } \\
\text { Sigma }\end{array}$ \\
\hline Mei & 21600 & 487,512 & 22570 & 3,5 \\
Juni & 21600 & 539,8 & 24991 & 3,5 \\
Juli & 21600 & 500 & 23148 & 3,5 \\
Agustus & 21600 & 450,984 & 20879 & 3,5 \\
September & 21600 & 473,984 & 21944 & 3,5 \\
\hline
\end{tabular}

\section{Analyze}

Dari hasil brainstorming yang telah dilakukan didapat beberapa kategori yang dicurigai menjadi akar penyebab tingginya loss di cooling water system (Gambar 1). Karena jumlah calon penyebab dirasa terlalu banyak maka dilakukan non group testing dengan cara mengurutkan prioritas berdasarkan masing masing pemikiran anggota lalu digunakan rumus $(1 \mathrm{n} / 2)+1$, hasil dari perhitungan tersebut digunakan untuk mengambil calon faktor penyebab dari atas.

Karena nilai $(1 * 8 / 2)+1=5$ maka diambil 5 data dengan peringkat teratas,yaitu backwash filter terlalu singkat, banyaknya Total Suspended solid yang terbawa saat hujan, Filter Overload, indikasi flow side stream tidak terbaca dan durasi filter service belum terbaca

Dari hasil Cause and Effect analysis (Gambar 1) dilakukan Failure Mode Effect Analysis (FMEA) untuk menentukan prioritas usulan perbaikan yang akan dilakukan. Untuk melakukan FMEA terlebih dahulu dilakukan brainstorming karyawan PT PBI untuk menentukan nilai Severity, Occurance, dan Detection. Setelah nilai dari masing - masing kriteria ditentukan, dilanjutkan dengan proses FMEA dengan cara penentuan poin kriteria 
dengan Risk Priority Number (RPN).

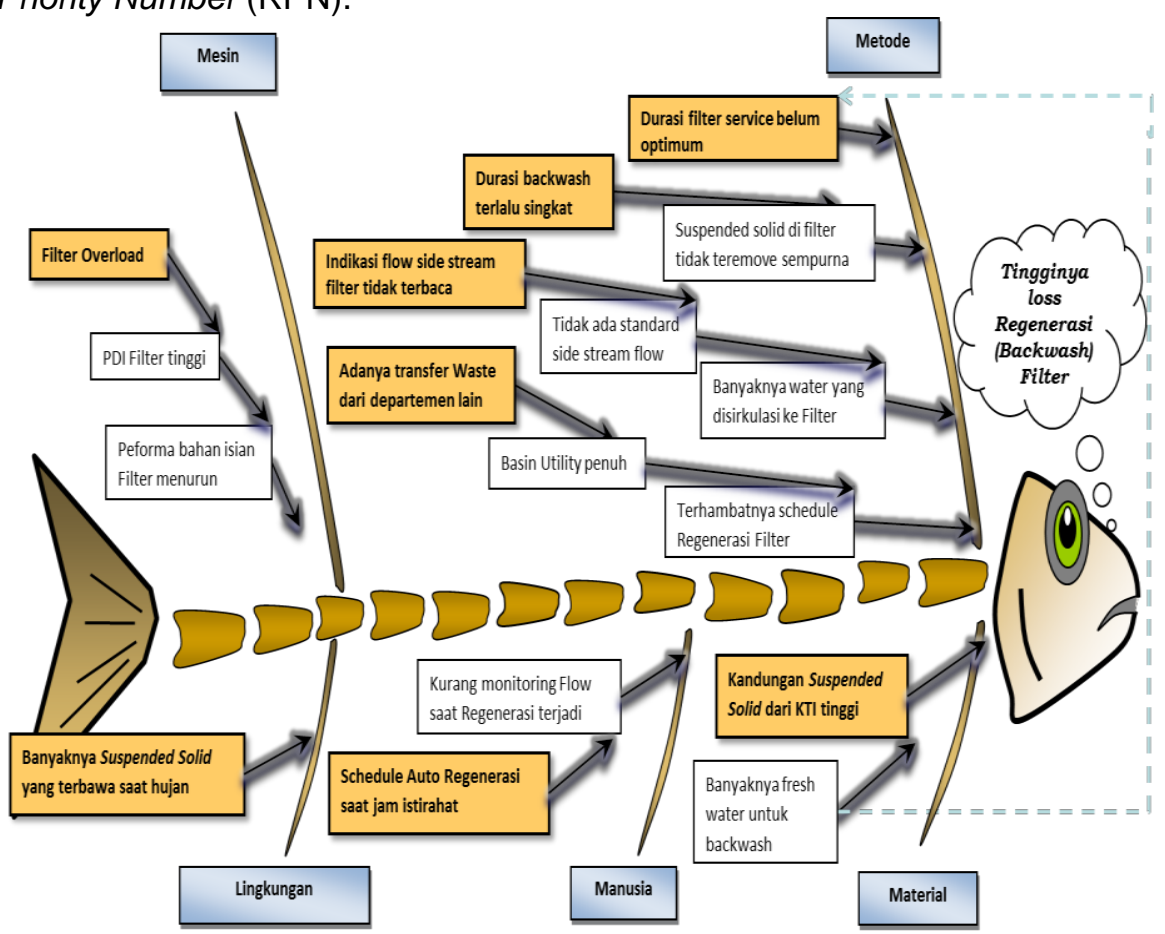

Gambar 1. Fishbone Diagram

Tabel 5. Failure Mode Effect Analysis (FMEA)

\begin{tabular}{|c|c|c|c|c|c|c|c|}
\hline Kategori & $\begin{array}{c}\text { Model } \\
\text { Kegagalan }\end{array}$ & $\begin{array}{l}\text { Penyebab } \\
\text { Kegagalan }\end{array}$ & $\begin{array}{c}\text { Akibat } \\
\text { Kegagalan }\end{array}$ & $S$ & $\mathrm{O}$ & $\mathrm{D}$ & RPN \\
\hline Metode & $\begin{array}{l}\text { Backwash } \\
\text { filter terlalu } \\
\text { singkat }\end{array}$ & $\begin{array}{l}\text { Design yang } \\
\text { diberikan } \\
\text { vendor belum } \\
\text { pernah } \\
\text { dievaluasi }\end{array}$ & $\begin{array}{c}\text { Jumlah TSS di } \\
\text { cooling water } \\
\text { tinggi sehingga } \\
\text { harus dilakukan } \\
\text { blowdown }\end{array}$ & 7 & 7 & 7 & 343 \\
\hline Lingkungan & $\begin{array}{c}\text { Banyak TSS } \\
\text { yang } \\
\text { terbawa saat } \\
\text { hujan }\end{array}$ & $\begin{array}{l}\text { Cooling Tower } \\
\text { memiliki design } \\
\text { yang terekspos } \\
\text { langsung ke } \\
\text { udara luar }\end{array}$ & $\begin{array}{l}\text { Jumlah TSS di } \\
\text { cooling water } \\
\text { tinggi sehingga } \\
\text { harus dilakukan } \\
\text { blowdown }\end{array}$ & 5 & 3 & 5 & 75 \\
\hline Mesin & Filter Overload & $\begin{array}{c}\text { Performa } \\
\text { material dalam } \\
\text { filter menurun }\end{array}$ & $\begin{array}{l}\text { Penyaringan } \\
\text { berkurang, TSS } \\
\text { tinggi, harus } \\
\text { blowdown }\end{array}$ & 5 & 3 & 5 & 75 \\
\hline Mesin & $\begin{array}{l}\text { Indikasi Flow } \\
\text { Side Stream } \\
\text { tidak terbaca }\end{array}$ & $\begin{array}{c}\text { Flow Indicator } \\
\text { kotor }\end{array}$ & $\begin{array}{l}\text { Terlalu banyak air } \\
\text { yang disirkulasikan } \\
\text { ke filter,banyak } \\
\text { yang terbuang }\end{array}$ & 7 & 7 & 5 & 245 \\
\hline Metode & $\begin{array}{l}\text { Durasi filter } \\
\text { Service } \\
\text { belum } \\
\text { optimum }\end{array}$ & $\begin{array}{c}\text { Design dari } \\
\text { vendor belum } \\
\text { pernah } \\
\text { direvisi }\end{array}$ & $\begin{array}{l}\text { Terlalu cepat } \\
\text { regenerasi } \\
\text { padahal kualitas } \\
\text { air masih baik }\end{array}$ & 7 & 7 & 7 & 343 \\
\hline
\end{tabular}


Dari penilaian RPN pada FMEA, faktor penyebab dengan prioritas tertinggi adalah waktu backwash filter yang terlalu singkat dan durasi servis belum optimum, disusul dengan indikasi flow side stream tidak terbaca lalu yang terakhir adalah TSS tinggi karena hujan dan filter overload.

\section{Improve}

Dari hasil FMEA dan brainstorming yang dilakukan, perbaikanakan dilakukan pada poin waktu backwash filter yang terlalu singkat dan durasi servis belum maksimal dan disusul dengan flow side stream tidak terbaca yang pada akhirnya semua mengakibatkan tingginya jumlah loss pada cooling water system, oleh karena itu faktor penyebab terjadinya kegagalan harus dianalisis lebih lanjut menggunakan $5 \mathrm{~W} 1 \mathrm{H}$ dengan hasil durasi backwash dari 15 menit menjadi 30 menit, regenerasi filter dilakukan menjadi tiap dua hari dan membersihkan rotary meter untuk monitor flow side stream (Tabel 6)

Tabel 5. Analisis $5 \mathrm{~W} 1 \mathrm{H}$ terhadap faktor penyebab dengan angka RPN tinggi

\begin{tabular}{|c|c|c|c|c|c|c|c|}
\hline No & Factor & Why & What & Where & When & Who & How \\
\hline \multirow[t]{2}{*}{1} & \multirow[t]{2}{*}{$\begin{array}{l}\text { Backwash filter terlalu } \\
\text { singkat }\end{array}$} & \multirow{2}{*}{$\begin{array}{l}\text { Untuk } \\
\text { memaksimalkan } \\
\text { performance filter }\end{array}$} & \multirow{2}{*}{$\begin{array}{l}\text { Menambah } \\
\text { durasi } \\
\text { backwash } \\
\text { filter }\end{array}$} & Panel & \multirow[t]{2}{*}{$\begin{array}{c}\text { November } \\
2017\end{array}$} & \multirow{2}{*}{$\begin{array}{l}\text { Ikhsan } \\
\quad \& \\
\text { Wildan }\end{array}$} & \multirow[t]{2}{*}{$\begin{array}{l}\text { Menambah durasi backwash } \\
\text { filter dari } 15 \text { menit ke } 30 \text { menit }\end{array}$} \\
\hline & & & & FA-8801 & & & \\
\hline 3 & $\begin{array}{l}\text { Durasi filter service } \\
\text { belum optimum }\end{array}$ & $\begin{array}{l}\text { Untuk mengurangi } \\
\text { backwash waste }\end{array}$ & $\begin{array}{l}\text { Mengubah } \\
\text { jadwal } \\
\text { backwash }\end{array}$ & FA-8801 & $\begin{array}{c}\text { November } \\
2017\end{array}$ & Masly & 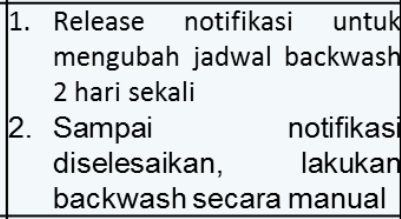 \\
\hline 4 & $\begin{array}{l}\text { Indikasi flow side stream } \\
\text { tidak terbaca }\end{array}$ & $\begin{array}{l}\text { Untuk memonitor } \\
\text { jumlah side stream } \\
\text { flow }\end{array}$ & $\begin{array}{l}\text { Cleaning } \\
\text { Flowmeter }\end{array}$ & FA-8801 & $\begin{array}{c}\text { November } \\
\text { ber } \\
2017\end{array}$ & Suhendro & $\begin{array}{l}\text { 1. Membuat notifikasi cleaning } \\
\text { rotameter } \\
\text { 2. Rutin cleaning } 1 \text { bulan } \\
\text { sekali sebagai kegiatan } \\
\text { AM }\end{array}$ \\
\hline
\end{tabular}

\section{Control}

Tahap control dilakukan untuk memastikan bahwa semua perbaikan yang dilakukan tepat sasaran, hal yang dilakukan pada tahap ini adalah:melakukan perawatan dan perbaikan mesin secara berkala, melakukan pengawasan terhadap perbaikan yang telah dilakukan, melakukan pencatatan loss setiap bulan setelah dilakukan perbaikan guna mengetahui efek perbaikan setelah dilakukan dan jika perbaikan dapat dibuktikan telah berhasil maka perlu dilakukan pembuatan standar baru agar perbaikan yang dilakukan dapat dijadikan acuan untuk pengerjaan bagian produksi yang bersangkutan.

Perbaikan yang telah dilakukan telah mampu meningkatkan nilai sigma selama 3 tahun terakhir menjadi 4,5 dari sebelumnya 3,5 (Tabel 6). Setelah tiga bulan dilakukan pengamatan dan hasil perbaikan tetap menunjukan hasil yang cukup baik maka dilakukan permintaan penggantian standar operasional pada system cooling water di PT. PBI. Jika permintaan diberi persetujuan oleh atasan maka selanjutnya standar baru akan digunakan sampai didapatkan perbaikan-perbaikan dengan hasil yang lebih baik dari hasil penelitian kali

Tabel 6. Nilai Sigma setelah perbaikan

\begin{tabular}{lllll}
\hline \multicolumn{1}{c}{ Bulan } & $\begin{array}{c}\text { Jumlah } \\
\text { Produksi }\end{array}$ & $\begin{array}{c}\text { Jumlah } \\
\text { Loss }\end{array}$ & DPMO & $\begin{array}{c}\text { Nilai } \\
\text { Sigma }\end{array}$ \\
\hline November & 21600 & 20,3 & 939 & 4,5 \\
Desember & 21600 & 21,4 & 990 & 4,5 \\
Januari & 21600 & 20,5 & 949 & 4,5 \\
\hline
\end{tabular}

\section{KESIMPULAN}

Berdasarkan analisa yang telah dilakukan diperoleh hasil bahwa akar penyebab masalah terjadinya cooling water loss adalah durasi backwash filter terlalu sedikit, durasi filter service belum optimum, dan flow side stream tidak terbaca. Usulan perbaikan yang dilakukan untuk menanggulangi masalah adalah dengan memperlama durasi backwash, menaikan waktu service sand filter menjadi dua hari sekali, dan membersihkan rotary meter agar flow side stream dapat selalu dimonitor. Perbaikan ini mampu mengurangi jumlah cooling water loss menjadi 20,3 di bulan oktober, 21,4 di bulan 
november dan 20,5 di bulan desember. Penurunan jumlah cooling water loss mampu meningkatkan nilai sigma dari 3,5 menjadi 4,5.

\section{DAFTAR PUSTAKA}

Antony, J. (2006). Six sigma for service processes. Business Process Management Journal, 12(2), 234-248. https://doi.org/10.1108/1463715061065755 8

Chakravorty, S. S. (2009). Six Sigma programs: An implementation model. International Journal of Production Economics, 119(1), $1-16$.

Kwak, Y. H., \& Anbari, F. T. (2006). Benefits, obstacles, and future of six sigma approach. Technovation, 26(5-6), 708-715. https://doi.org/10.1016/j.technovation.2004. 10.003

Pyzdek, T., \& Keller, P. A. (2010). The Six Sigma handbook: a complete guide for green belts, black belts, and managers at all levels. McGraw-Hill Companies.

Rohimudin, R., Dwiputra, G. A., \& Supriyadi, S. (2016). Analisis Defect pada Hasil Pengelasan Plate Konstruksi Baja dengan Metode Six Sigma. Jurnal INTECH Teknik Industri Universitas Serang Raya, 2(1), 110.

Rosihin, R., Ulinnuha, L. M., \& Cahyadi, D. (2017). Analisis Pengendalian Kualitas Super Absorbent Polymer Dengan Menggunakan Metode Six Sigma. Jurnal Sistem Dan Manajemen Industri, 1(1), 1928. https://doi.org/10.30656/jsmi.v1i1.170

Schroeder, R. G., Linderman, K., Liedtke, C., \& Choo, A. S. (2008). Six Sigma: Definition and underlying theory. Journal of Operations Management, 26(4), 536-554. https://doi.org/10.1016/j.jom.2007.06.007

Supriyadi, S., Ramayanti, G., \& Aditia, Y. (2017). Analisa Kualitas Precious Slag Ball dengan Pendekatan Six Sigma. In Proceedings Seminar IImiah Nasional (pp. 45-58). Universitas Pamulang.

Windarti, T. (2014). Pengendalian kualitas untuk meminimasi produk cacat pada proses produksi besi beton. J@ Ti Undip: Jurnal Teknik Industri, 9(3), 173-180. 